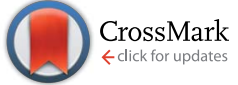

Cite this: RSC Adv., 2016, 6, 110916

\title{
Study of phase inversion parameters for EB-cured polysulfone-based membranes
}

\begin{abstract}
Veysi Altun, ${ }^{a}$ Michael Bielmann ${ }^{\mathrm{b}}$ and Ivo F. J. Vankelecom ${ }^{\star a}$
Asymmetric EB-cross-linked polysulfone (PSU) membranes suitable for solvent resistant nanofiltration (SRNF) were prepared via the phase inversion method. The influence of phase inversion parameters including polymer concentration, evaporation time prior to immersion and co-solvent/solvent ratio was investigated to optimize the separation performance. When the PSU concentration increased from 15 $w t \%$ to $21 \mathrm{wt} \%$, rose bengal (RB) rejection varied from 84.7 to $94.3 \%$ and isopropanol (IPA) permeance decreased from 0.051 to $0.015 \mathrm{~L} \mathrm{~m}^{-2} \mathrm{~h}^{-1}$ bar $^{-1}$. Rejection increased from 88.6 to $94.7 \%$, while permeance decreased from 0.039 to $0.007 \mathrm{~L} \mathrm{~m}^{-2} \mathrm{~h}^{-1}$ bar $^{-1}$ with increasing evaporation time from 0 to $100 \mathrm{~s}$ for the PSU membranes cast from a solution that contained a THF/NMP ratio of 15/85. A similar impact was also obtained when the co-solvent/solvent (THF/NMP) ratio was increased from 0/100 to $30 / 70$ at 30 s evaporation time: rejection increased from 86.3 to $96.1 \%$, while permeance decreased from 0.042 to $0.011 \mathrm{~L} \mathrm{~m}^{-2} \mathrm{~h}^{-1}$ bar $^{-1}$. The EB-cured PSU membranes were further characterized by scanning electron microscopy (SEM) and solvent resistance tests.
\end{abstract}

Received 30th September 2016 Accepted 9th November 2016

DOI: 10.1039/c6ra24340a

www.rsc.org/advances modification of PSU membranes..$^{\mathbf{1 5 , 1 9 , 2 0}}$ Recently, we have developed an EB-depth curing method to prepare highly stable PSU-based membranes. ${ }^{21}$ In that approach, EB-irradiation was performed to PSU-membranes containing acrylate crosslinkers, synthesized via non-solvent induced phase separation (NIPS). ${ }^{6}$ Membrane performance, morphology and solvent resistance were investigated using various acrylate functionalities and EB-doses.

Even small variations in the composition of the casting solutions and synthesis procedures may have strong effects on the final SRNF-membrane performance and morphology. ${ }^{6,22-30} \mathrm{~A}$ detailed investigation of the phase inversion parameters was thus performed here, i.e. higher permeances combined with improved rejections, to obtain better performances with EB cross-linked PSU-based membranes via this method. From the previous study, a specific EB-depth cured membrane was thus selected for further optimization by tuning following crucial phase inversion parameters: the polymer concentration in the casting solution, evaporation time prior to immersion, and solvent/co-solvent ratio. The SRNF performance, cross-section morphology and solvent stability of the resultant EB-cured PSU membrane were analysed.

\section{Experimental}

\subsection{Materials}

PSU (Udel P-1700 LCD, $M_{\mathrm{n}}=21000 \mathrm{~g} \mathrm{~mol}^{-1}$ ) was kindly supplied by Solvay and dried overnight at $100{ }^{\circ} \mathrm{C}$ prior to use. The polyethylene terephthalate (PET) non-woven fabric Novatexx 2413 was kindly provided by Freudenberg (Germany).
${ }^{a}$ Centre for Surface Chemistry and Catalysis, KU Leuven, Celestijnenlaan 200 F, PO Box 2461, 3001 Leuven, Belgium. E-mail: ivo.vankelecom@kuleuven.be; Fax: +32 1632 1998; Tel: +32 16321594

${ }^{b}$ ebeam Technologies, Herrengasse 10, 3175 Wünnewil-Flamatt, Switzerland 
Dipentaerythritol penta-acrylate (SR399LV, Sartomer, >90\%) was used as cross-linker (Fig. 1). Rose bengal (RB, $1017.64 \mathrm{~g}$ $\mathrm{mol}^{-1}$ ) was purchased from Sigma-Aldrich. Isopropanol (99.5\%, IPA), $N$-methylpyrrolidone (99\%, NMP), tetrahydrofuran (99.5\%, THF), acetone (99.8\%), $N, N$-dimethylacetamide (99\%, DMAc), toluene (99.8\%), butylacetate (99\%) $\mathrm{N}, \mathrm{N}$-dimethylformamide (99.5\%, DMF) were obtained from Acros and used as received.

\subsection{Membrane synthesis}

Three different series of membranes were prepared to determine the influence of the polymer concentration, evaporation time and role of co-solvent as phase inversion parameters on the performance and morphology of the EB-cured PSUmembranes. In the first series, the influence of the polymer concentration was analysed by using an NMP-based solution with 15, 18 and 21 wt\% of PSU. In the second series, the influence of the evaporation time was analysed by using an NMP-based solution containing THF as a co-solvent in a 85/15 ratio. Evaporation times of $0,10,20,30,60$ or $100 \mathrm{~s}$ were applied. It has to be mentioned that all cast films were evaporated for roughly about $5 \mathrm{~s}$ extra, which was the required time to move the cast film from the casting equipment to the nonsolvent (deionized water) bath. In the third series, the influence of co-solvent was analysed by using an NMP (boiling point, $202{ }^{\circ} \mathrm{C}$ ) based solution with THF (boiling point, $66^{\circ} \mathrm{C}$ ) as a cosolvent keeping a constant evaporation time of $30 \mathrm{~s}$, but with various ratios of THF/NMP: 0/100, 5/95, 10/90, 15/85, 20/80 and $30 / 70$. All samples were prepared at room temperature under atmospheric conditions. In the second and third series, the polymer concentration was kept constant at $21 \mathrm{wt} \%$. All samples were prepared by using cross-linker at an amount of $5 \mathrm{wt} \%$. The solutions were cast onto an NMP-saturated PET non-woven fabric (Novatexx 2413) using an automated casting knife with a thickness of $200 \mu \mathrm{m}\left(1.81 \mathrm{~m} \mathrm{~min}^{-1}\right.$, Braive Instruments, Belgium). Membranes were stored in deionized water until the EB cross-linking process.

\subsection{EB-curing of asymmetric PSU-based membranes}

Membranes were cross-linked using EB-curing (ebeam Technologies, EBLab200, Switzerland) at a $200 \mathrm{kV}$ accelerating voltage and $9.3 \mathrm{~mA}$ beam current with a maximum dose of 100 kGy given during each pass. In accordance with previous study, ${ }^{21}$ an energy dose of $300 \mathrm{kGy}$ was chosen to cure the membranes. Some cured PSU membranes were impregnated after EB-curing to enhance the flexibility and avoid pore collapse by soaking them in a solution comprising $40 \%(\mathrm{v} / \mathrm{v})$ of

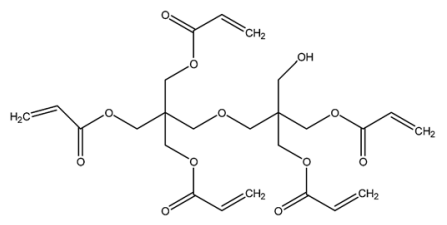

Fig. 1 Chemical structure of the dipentaerythritol penta-acrylate. glycerol in propan-2-ol for $48 \mathrm{~h}$ at room temperature, and subsequently air-dried. SEM was applied to the nonimpregnated parts of the membranes.

\subsection{Scanning electron microscopy (SEM)}

Membrane cross-section images were obtained using a Philips XL30 FEG scanning electron microscope. The membrane samples were freeze-cracked in liquid nitrogen. Samples were coated with a 1.5-2 nm gold layer using a Cressington HR208 high-resolution sputter coater to reduce sample charging under the electron beam.

\subsection{Viscosity measurements}

The viscosity of the casting solutions measurements was measured with an Anton Paar MCR501 rheometer with a coneplane geometry with solvent trap at $20{ }^{\circ} \mathrm{C}$. The sample temperature was controlled by a Peltier element with high accuracy. Viscosity at different shear rates was measured in steady-shear flow from 0.01 to 100 1/s. Data acquisition and analysis was done using RheoPlus software (Anton Paar GmbH, Austria).

\subsection{Solvent stability}

The solvent resistance of the PSU-membranes was determined by visual inspection after immersing membrane samples in various solvents at room temperature for at least $24 \mathrm{~h}$.

\subsection{Filtration tests}

Filtrations were performed at room temperature at selected pressures in a high-throughput filtration module (HTML, Belgium), ${ }^{2,31}$ allowing for simultaneous filtrations of 16 membranes. Membrane coupons were supported by a porous stainless steel disc and sealed with Viton ${ }^{\circledR}$ O-rings. The active membrane surface area was $0.000452 \mathrm{~m}^{2}$. A solution of $17.5 \mu \mathrm{M}$ rose bengal (1017 Da) in IPA was used as feed and stirred magnetically at $400 \mathrm{rpm}$ to reduce concentration polarization. Permeance $\left(P, \mathrm{~L} \mathrm{~m}^{-2} \mathrm{~h}^{-1} \operatorname{bar}^{-1}\right)$ was determined gravimetrically by weighing the collected permeate. Rejection $(R, \%)$ is defined as $\left(1-C_{\mathrm{p}} / C_{\mathrm{f}}\right) \times 100$, where $C_{\mathrm{f}}$ and $C_{\mathrm{p}}$ denote the solute concentrations in the initial feed and in the permeate respectively. These concentrations were measured on a Perkin-Elmer lambda $12 \mathrm{UV}$-Vis spectrophotometer at $555 \mathrm{~nm}$.

\section{Results and discussion}

\subsection{Influence of PSU concentration}

3.1.1 Filtration performance. Fig. 2 represents the IPA permeance and $\mathrm{RB}$ rejection data obtained with EB-cured PSUmembranes prepared from casting solutions with polymer concentrations between $15 \mathrm{wt} \%$ and $21 \mathrm{wt} \%$. The THF/NMP ratio and evaporation time of the cast films were kept constant as $15 / 85$ and $30 \mathrm{~s}$ respectively prior to immersion precipitation. The IPA permeances decreased with higher PSU concentration from 0.051 to $0.015 \mathrm{~L} \mathrm{~m}^{-2} \mathrm{~h}^{-1} \mathrm{bar}^{-1}$, while the $\mathrm{RB}$ rejections slightly increased with increasing PSU 


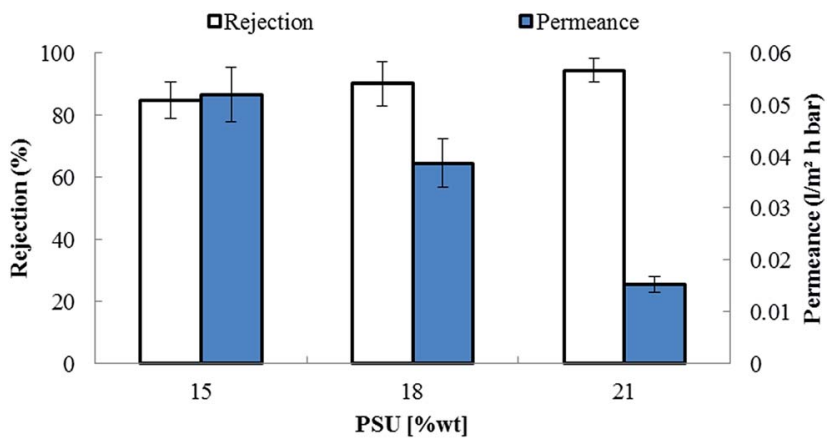

Fig. 2 Effect of PSU concentration in the casting solution on the separation performance of EB-cured PSU-membranes (conditions: $30 \mathrm{~s}$ of evaporation time and $15 / 85$ ratio of THF/NMP).

concentration, hardly above experimental error. Overall, the changes in rejection were not as significant as expected. This might be explained by the excessive cross-linking of all prepared membranes that takes place due to the intrinsic energy of EB as was reported in our previous study. ${ }^{21}$ This seemingly densifies all skin layers of the membranes to a very large extend.

The general effect of polymer concentration in the casting solution is in accordance with literature where it has been studied already for e.g. polyimide (PI) and PSU-based SRNF membranes..$^{27,32}$ Due to the increasing initial polymer concentration in the casting solution, a higher concentration is present at the polymer/non-solvent interface which retards the diffusion of non-solvent. Thus, demixing is delayed and a denser or thicker skin layer is formed which especially results here in a lowered permeance, which is obviously not desired. ${ }^{1}$

3.1.2 Membrane morphology. Fig. 3 illustrates the crosssections of the membranes consisting of $15 \mathrm{wt} \%, 18 \mathrm{wt} \%$ and $21 \mathrm{wt} \%$ of PSU. It is clear that the number of macrovoids decreases and their size increases with increasing polymer concentration. Increasing the polymer concentration in the casting solution leads to elevated polymer concentrations at the interface of the cast membrane and the precipitation bath. As shown in Table 1, the viscosity of casting solution increases from 2.17 to 2.93 Pa s by increasing the PSU concentration from 15 to $21 \mathrm{wt} \%$. In this way, the higher viscosity of the film slows down the non-solvent diffusion and thus limits the macrovoid formation..$^{22,33}$

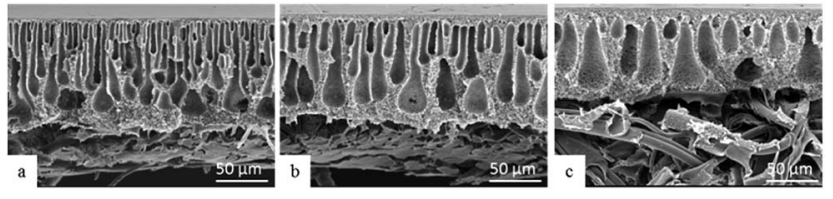

Fig. 3 Effect of the PSU concentration in the casting solution on the morphology resulting EB-cured PSU membranes as observed in SEM cross-section images: (a) 15 wt\%, (b) 18 wt\%, (c) 21 wt\% in THF/NMP (15/85).
Table 1 Viscosity of the casting solutions containing various PSU concentration

\begin{tabular}{ll}
\hline $\begin{array}{l}\text { PSU concentration } \\
(\mathrm{wt} \%)\end{array}$ & $\begin{array}{l}\text { Viscosity } \\
(\mathrm{Pa} \mathrm{s})\end{array}$ \\
\hline & \\
15 & 2.17 \\
18 & 2.49 \\
& 2.93
\end{tabular}

\subsection{Influence of evaporation time}

3.2.1 Filtration performance. One of the commonly used methods to have a denser membrane skin layer is evaporation of volatile (co-)solvents from the casting solution before coagulation. ${ }^{22,23,27,32}$ This process leads to the formation of a thinlayer at the surface of the membrane which creates a locally elevated polymer concentration. The resultant film layer induces delayed demixing as the mass transfer resistance between the non-solvent bath and the bulk of the membrane

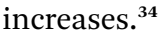

Literature related to this parameter in SRNF-membranes seems very system dependent. Evaporation times of 0 to $40 \mathrm{~s}$ for PI (P84) membranes based on DMF/DIO casting solutions did not influence the dense top layer formation. ${ }^{22}$ On the other hand, increasing evaporation time from 0 to $120 \mathrm{~s}$ for another PI (Matrimid) membrane based on an NMP/THF casting solution resulted in a rejections and lower permeances. ${ }^{32}$ In the case of PSU-based SRNF-membranes, a constant decrease in permeance was observed with higher evaporation time, but the rejection increase stopped after a certain time and remained stable afterwards. ${ }^{27}$

Six different evaporation times of $0,10,20,30,60$ or $100 \mathrm{~s}$ were applied for evaporation of THF before dipping the cast membranes in the water bath. The IPA permeance decreased from 0.039 to $0.007 \mathrm{~L} \mathrm{~m}^{-2} \mathrm{~h}^{-1} \mathrm{bar}^{-1}$, while $\mathrm{RB}$ retention slightly improved from 88.6 to $94.7 \%$ by increasing the evaporation time (Fig. 4). After $30 \mathrm{~s}$, effects on rejection and flux became less pronounced, especially the rejection. Evaporation times longer

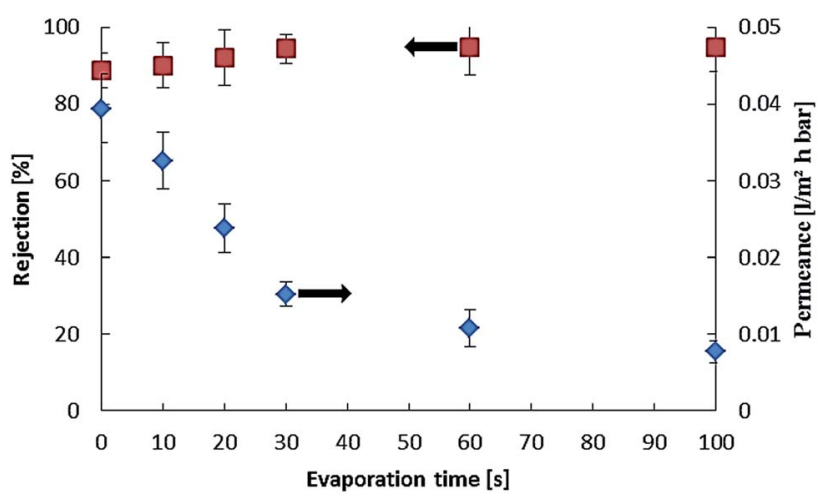

Fig. 4 Effect of evaporation time before immersion in the non-solvent bath on the separation performance of EB-cured PSU/THF-based membranes in terms of rejection and permeance for a RB/IPA feed (conditions: 15/85 ratio of THF/NMP). 
than $30 \mathrm{~s}$ are thus not beneficial for this system, while shorter times show a typical trade-off between flux and rejection, hence creating an application dependent optimum.

3.2.2 Membrane morphology. Varying the evaporation time remarkably affected the membrane morphology, as illustrated in the SEM pictures (Fig. 5). Only membranes prepared very short evaporation times showed small macrovoids immediately under the surface layer. At the highest evaporation times (100 s), even an almost full disappearance of macrovoids could be observed. The reason to turn the macrovoid structure into a more sponge-like structure is generally attributed to delayed demixing, here provoked by the formation of a stronger mass transfer resistance for the non-solvent penetrate the film after the evaporation step.

\subsection{Influence of co-solvent concentration}

3.3.1 Filtration performance. The distinct influence of cosolvent addition on the performance and morphology of asymmetric membranes has been investigated by several researchers. $^{22,32,35}$

Fig. 6 demonstrates the effect of the co-solvent/solvent ratio (THF/NMP) on the separation performance of EB-cured PSUmembranes. THF evaporates considerably during the evaporation step, owing to its low boiling point $\left(66^{\circ} \mathrm{C}\right)$. In general, it is
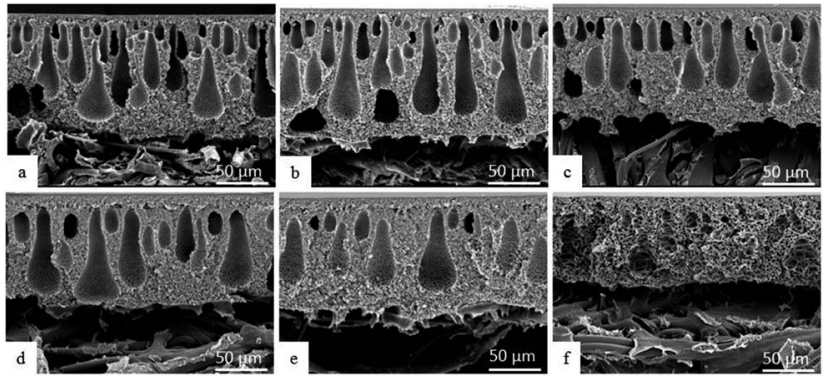

Fig. 5 Effect of evaporation time before immersion in the non-solvent bath on the morphology of the EBU-cured PSU membranes: (a) $0 \mathrm{~s}$, (b) $10 \mathrm{~s}$, (c) $20 \mathrm{~s}$, (d) $30 \mathrm{~s}$, (e) $60 \mathrm{~s}$, (f) $100 \mathrm{~s}$.

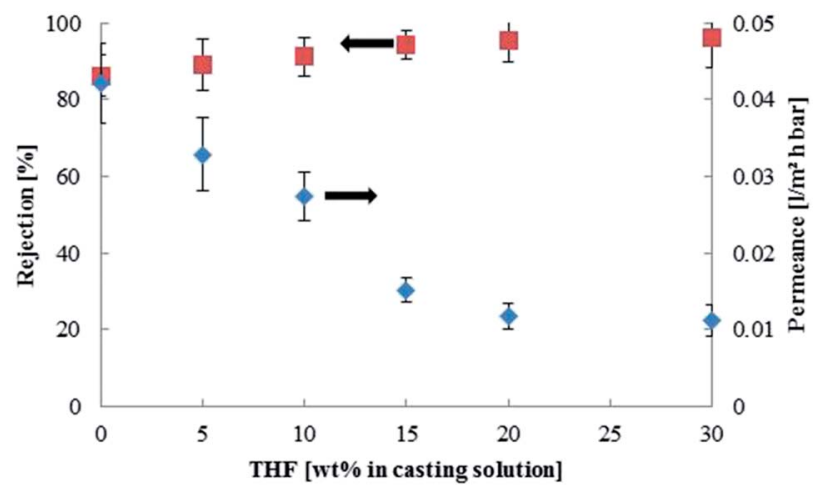

Fig. 6 Effect of co-solvent (THF) amount in the PSU casting solution on the separation performance of the EB-cured PSU-membranes (conditions: $30 \mathrm{~s}$ of evaporation time). observed that adding more THF to the casting solution results in reduced IPA permeances and increased $\mathrm{RB}$ rejections. The ideal THF/NMP ratio can be assumed roughly to be $15 / 85$, since beyond this ratio, permeance still decreased, but rejection stayed almost constant. It can be seen that the higher THF concentration in the PSU casting solution increased the rejection (Fig. 6). However, IPA flux was still very low to fulfill SRNF applicability. ${ }^{9}$

3.3.2 Membrane morphology. The increase in THF/NMP weight ratio from $0 / 100$ to $30 / 70$ in the casting solutions notably influenced the membrane morphology, as shown in the SEM pictures (Fig. 7). The number of macrovoids decreased gradually with increasing THF content. In line with 3.1.2, this could be explained by an increased mass transfer barrier at higher THF concentrations leading to delayed demixing, inducing less macrovoids in the membranes. ${ }^{36,37}$

\subsection{Solvent resistance}

Table 2 illustrates the stability of the non-cured and the EBcured membranes in various solvents. All membranes were stable in IPA. The EB cross-linked PSU membranes were stable in acetone and butyl acetate, while the non-cured membrane swelled upon immersion in these solvents. The EB-cured PSU membranes were also stable in toluene, while the reference membrane fully dissolved. Furthermore, the EB cross-linked PSU membrane swelled without dissolving after immersion in DMF, THF and NMP, while the reference membrane dissolved

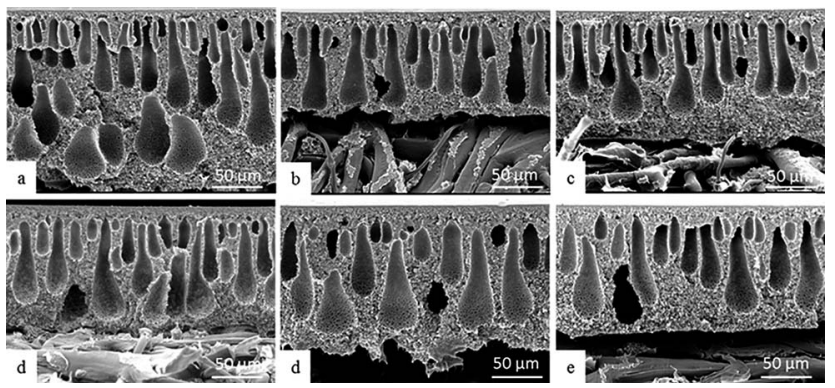

Fig. 7 Effect of co-solvent/solvent ratio (THF/NMP) in the PSU casting solution on the morphology of the EB-cured PSU membranes: (a) [0/ 100], (b) [5/95], (c) [10/90], (d) [15/85], (e) [20/80], (f) [30/70].

Table 2 Solvent stability of the non-cured (without additive) and EBcured PSU membranes ${ }^{a}$

\begin{tabular}{lll}
\hline Solvent & Non-cured & EB-cured \\
\hline IPA & + & + \\
Acetone & $\times$ & + \\
Butyl acetate & $\times$ & + \\
Toluene & - & + \\
THF & - & $\times$ \\
NMP & - & $\times$ \\
DMF & - & $\times$ \\
DMAc & - & $\times$ \\
$a+$ stable, $\times$ swelling, - dissolution. &
\end{tabular}


fully. Hence, the EB irradiation obviously enhanced the solvent stability of the PSU membranes.

\section{Conclusions}

This study focused on the impact of various phase inversion parameters for the preparation of solvent stable EB-cured PSU membranes via NIPS in an attempt to create useful SRNFmembranes combining high rejection with high flux. Polymer concentration, evaporation time before immersion and cosolvent/solvent ratio were varied during membrane preparation to control the EB cross-linked membrane performance. Higher polymer concentrations in the casting solution led to a slight increase in RB rejection but a strong decrease in IPA permeance. Longer evaporation times prior to the precipitation continuously lowered the permeance till $0.007 \mathrm{~L} \mathrm{~m}^{-2} \mathrm{~h}^{-1} \mathrm{bar}^{-1}$ (at $100 \mathrm{~s}$ ), while no significant change was observed in rejection. Depending on the targeted final application of the EB-cured membranes, evaporation times may be limited to $10 \mathrm{~s}$ or even totally eliminated. Addition of a more volatile co-solvent (THF) to the casting solution caused constant decline in permeance up to $0.011 \mathrm{~L} \mathrm{~m}^{-2} \mathrm{~h}^{-1} \mathrm{bar}^{-1}$, while the rejection increased to $96.1 \%$. The morphological analysis demonstrated that synthesized membranes were influenced markedly by the phase inversion parameters as anticipated. The most distinct change was detected by varying the time of the evaporation step, as the macrovoid structure turned to a totally spongy structure with increasing evaporation time. In conclusion, despite varying all these phase inversion parameters, the flux generally remained too low for membranes to become really useful in SRNF. However, these membranes still may be used for applications where more dense structures are required, like in gas separation or pervaporation.

\section{Acknowledgements}

V. Altun acknowledges the European Commission - Education, Audiovisual and Culture Executive Agency (EACEA), for his PhD scholarship under the program: Erasmus Mundus Doctorate in Membrane Engineering - EUDIME (FPA N ${ }^{\circ} 2011$ 0014, Edition II, http://eudime.unical.it/). We are also grateful for the financial support from the OT (11/061) funding from KU Leuven and the I. A. P-P. A. I. grant (IAP 7/05) from the Belgian Federal Government.

\section{Notes and references}

$1 \mathrm{~J}$. Mulder, Basic principles of membrane technology, Springer Science \& Business Media, 2012.

2 M. Ulbricht, Polymer, 2006, 47, 2217-2262.

3 C. Dong, Z. Wang, C. Yi and S. Wang, J. Appl. Polym. Sci., 2006, 101, 1885-1891.

4 J.-N. Shen, L.-G. Wu, J.-H. Qiu and C.-J. Gao, J. Appl. Polym. Sci., 2007, 103, 1959-1965.

5 S. Hermans, H. Mariën, C. Van Goethem and I. F. J. Vankelecom, Curr. Opin. Chem. Eng., 2015, 8, 45-54.
6 A. K. Hołda and I. F. J. Vankelecom, J. Appl. Polym. Sci., 2015, 132, 42130-42147.

7 I. Strużyńska-Piron, J. Loccufier, L. Vanmaele and I. F. J. Vankelecom, Macromol. Chem. Phys., 2014, 215, 614623.

8 A. K. Hołda and I. F. J. Vankelecom, J. Membr. Sci., 2014, 450, 512-521.

9 P. Vandezande, L. E. M. Gevers and I. F. J. Vankelecom, Chem. Soc. Rev., 2008, 37, 365-405.

10 K. Vanherck, G. Koeckelberghs and I. F. J. Vankelecom, Prog. Polym. Sci., 2013, 38, 874-896.

11 Y. H. See Toh, F. W. Lim and A. G. Livingston, J. Membr. Sci., 2007, 301, 3-10.

12 S.-P. Sun, S.-Y. Chan, W. Xing, Y. Wang and T.-S. Chung, ACS Sustainable Chem. Eng., 2015, 3, 3019-3023.

13 K. Majewska-Nowak, Desalination, 1989, 71, 83-95.

14 M. Stephan, D. Pospiech, R. Heidel, T. Hoffmann, D. Voigt and H. Dorschner, Polym. Degrad. Stab., 2005, 90, 379-385.

15 A. Schulze, B. Marquardt, S. Kaczmarek, R. Schubert, A. Prager and M. R. Buchmeiser, Macromol. Rapid Commun., 2010, 31, 467-472.

16 H. Yamagishi, J. V. Crivello and G. Belfort, J. Membr. Sci., 1995, 105, 237-247.

17 M. M. Nasef and O. Güven, Prog. Polym. Sci., 2012, 37, 15971656.

18 W. Mondelaers, Nucl. Instrum. Methods Phys. Res., Sect. B, 1998, 139, 43-50.

19 H.-M. Xu, J.-F. Wei and X.-L. Wang, Desalination, 2014, 346, 122-130.

20 B. Deng, J. Li, Z. Hou, S. Yao, L. Shi, G. Liang and K. Sheng, Radiat. Phys. Chem., 2008, 77, 898-906.

21 V. Altun, M. Bielmann and I. F. J. Vankelecom, RSC Adv., 2016, 6, 55526-55533.

22 I. Soroko, M. Makowski, F. Spill and A. Livingston, J. Membr. Sci., 2011, 381, 163-171.

23 K. Hendrix, G. Koeckelberghs and I. F. J. Vankelecom, J. Membr. Sci., 2014, 452, 241-252.

24 H. Yanagishita, T. Nakane and H. Yoshitome, J. Membr. Sci., 1994, 89, 215-221.

25 P. Vandezande, L. E. M. Gevers, J. S. Paul, I. F. J. Vankelecom and P. A. Jacobs, J. Membr. Sci., 2005, 250, 305-310.

26 F. G. Paulsen, S. S. Shojaie and W. B. Krantz, J. Membr. Sci., 1994, 91, 265-282.

27 A. K. Hołda, B. Aernouts, W. Saeys and I. F. J. Vankelecom, J. Membr. Sci., 2013, 442, 196-205.

28 N. Leblanc, D. Le Cerf, C. Chappey, D. Langevin, M. Métayer and G. Muller, J. Appl. Polym. Sci., 2003, 89, 1838-1848.

29 J. Ren, R. Wang, T.-S. Chung, D. F. Li and Y. Liu, J. Membr. Sci., 2003, 222, 133-147.

30 K. Hendrix, M. Vaneynde, G. Koeckelberghs and I. F. J. Vankelecom, J. Membr. Sci., 2013, 447, 96-106.

31 High Throughput Membrane Systems Leuven, http:// www.html-membrane.be.

32 P. Vandezande, X. Li, L. E. M. Gevers and I. F. J. Vankelecom, J. Membr. Sci., 2009, 330, 307-318.

33 A. F. Ismail and A. R. Hassan, J. Membr. Sci., 2006, 270, 5772. 
34 J. R. Hwang, S. H. Koo, J. H. Kim, A. Higuchi and T. M. Tak, J. Appl. Polym. Sci., 1996, 60, 1343-1348.

35 I. Ahmed, A. Idris, A. Hussain, Z. A. M. Yusof and M. Saad Khan, Chem. Eng. Technol., 2013, 36, 1683-1690.
36 A. F. Ismail and P. Y. Lai, Sep. Purif. Technol., 2003, 33, 127143.

37 H. Shimizu, H. Kawakami and S. Nagaoka, Polym. Adv. Technol., 2002, 13, 370-380. 